\title{
Early muscle reinnervation by means of end-to-side neurorrhaphy in an experimental model
}

\author{
Araceli Pérez ${ }^{1}$, Rafael Reynoso², Rosa M. Romero², Angélica González², Jorge Ochoa ${ }^{2}$, Dulce H. Gutiérrez ${ }^{4}$ \\ Damián Palafox ${ }^{1}$
}

${ }^{1}$ Department of Plastic Surgery, General Hospital "Dr. Manuel Gea Gonzalez”, Mexico City 14080, Mexico.

${ }^{2}$ Department of Morphology of Cell and Tissue, National Pediatric Institute, Mexico City 14080, Mexico.

${ }^{3}$ Department of Plastic Surgery, Hospital Angeles, Mexico City 14080, Mexico.

${ }^{4}$ Department of Health Sciences, Technological University of Mexico, Mexico City 14080, Mexico.

Correspondence to: Dr. Araceli Pérez, Department of Plastic Surgery, General Hospital “Dr. Manuel Gea Gonzalez”, Mexico City 14080, Mexico. E-mail: dra.araceliperez@hotmail.com

How to cite this article: Pérez A, Reynoso R, Romero RM, González A, Ochoa J, Gutiérrez DH, Palafox D. Early muscle reinnervation by means of end-to-side neurorrhaphy in an experimental model. Plast Aesthet Res 2017;4:18-23.

\begin{abstract}
Article history:
Received: 01-11-2016

Accepted: 05-11-2016

Published: 22-02-2017

Key words:

Nerve transfer,

neurorrhaphy,

muscle reinnervation,

nerve repair
\end{abstract}

\section{ABSTRACT}

Aim: The aim of the study was to provide early muscular reinnervation to avoid muscle atrophy and functional loss in an experimental model. Methods: Fifty rats were divided into five groups. In group 0 (control group) only nerve dissection was performed. Total peroneal nerve section was performed in the remaining groups. Immediate end-to-end neurorrhaphy (EEN) was made in group 1. In group 2, an end-to-side neurorrhaphy (ESN) was performed from the tibial nerve to the peroneal nerve. In group 3, a direct EEN, plus an ESN, were used as a nerve graft as a bridge from the donor nerve (tibial); all nerve coaptations were performed through an epineural window. In group 4, only a neurotomy was made without any type of reconstruction. Results: Neural diameters were similar in groups 0,1 , and $3(38 \pm 1 \mu \mathrm{m}, 31 \pm 6 \mu \mathrm{m}, 32 \pm 3 \mu \mathrm{m})$. Neural fibers in group 3 had an $18 \%$ increase in the number of axons $(P<0.001)$ when compared to group 0 . Group $2(28 \pm 1 \mu \mathrm{m})$ and group $4(19 \pm 3 \mu \mathrm{m})$ had diminished diameters with a lower index of muscle regeneration. Animals in group 4 presented with “clawed” lower extremities and had difficulty with ambulation. Neural graft diameters was similar in groups 2 and 3 (33 $\pm 4 \mu \mathrm{m}, 31 \pm 3 \mu \mathrm{m})$, but axon density was significantly higher in group 3 (53 $\pm 6 \mu \mathrm{m}, 39$ $\pm 8 \mu \mathrm{m})(P<0.001)$. Axon density was $36 \%$ higher when the combination of EEN and ESN with a neural graft through an epineural window was performed. Conclusion: This study revealed that the combination of EEN and ESN repairs with the addition of a neural graft provides a lower index of muscle fiber destruction, and can be a reliable method for reconstruction in high neural injuries. 


\section{INTRODUCTION}

End-to-end neurorrhaphy (EEN) is the conventional reconstructive method for patients with peripheral nerve injuries. In some cases, as in patients with complex upper extremity trauma and/or extensive oncologic resections, an end-to-side neurorrhaphy (ESN) is considered to be a good alternative for neural reconstruction. ${ }^{[1-3]}$ However, this technique (ESN) has been abandoned by some surgeons secondary to discouraging functional outcomes. ${ }^{[4-6]}$ Viterbo et al..$^{[7,8]}$ has stated that ESN from a "healthy" nerve can "bridge" a neurological deficit, and indeed the outcomes from this type of surgery are better than those obtained from end-to-end coaptation. End-to-side nerve coaptation has also been used for patients with unilateral facial paralysis with good results. ${ }^{[9,10]}$ There are experimental models in which the orbicularis occuli muscle has been re-innervated with this technique. ${ }^{[11]}$

Patients with upper extremity proximal nerve injuries may require more than one year to achieve reinnervation in the distal extremity (during this time, axonal growth takes place). However, full reinnervation does not imply full recovery given the risk of often irreversible and uncorrectable muscle contracture and joint stiffness. In clinical studies, ESN has proven its usefulness by improving sensation alone. ${ }^{[6]}$
The current study was conducted to evaluate the provision of early muscular reinnervation to avoid muscle atrophy and function loss.

\section{METHODS}

From January 2008 to November 2008, fifty male adult Wistar rats were used for study. Their weight ranged from 350 to $400 \mathrm{~g}$ and they were divided into 5 groups of 10 rats each. Before and after surgery, the animals were housed in plastic boxes, with a 12-h light/dark cycle, and were given free access to food and water.

The measured criteria included anatomic changes of the leg, difficulty with ambulation, and microscopic neural and muscle morphology of the implied nerves and muscles. All the study rats were analyzed 90 days after the procedure.

The rats were anesthetized with an intraperitoneal injection of a 1:10 pentobarbital solution $(60 \mathrm{mg} / \mathrm{mL})$ at a conventional dosage. During the procedure, a dose of $0.1-0.2 \mathrm{~mL}$ of the same solution was administered as needed. The procedure was performed on the peroneal and tibial nerves of the right lower extremity. In group 0, nerves were dissected and exposed without sectioning. In the remaining groups, a neurotomy of the peroneal nerve was made $20 \mathrm{~mm}$ proximal to its
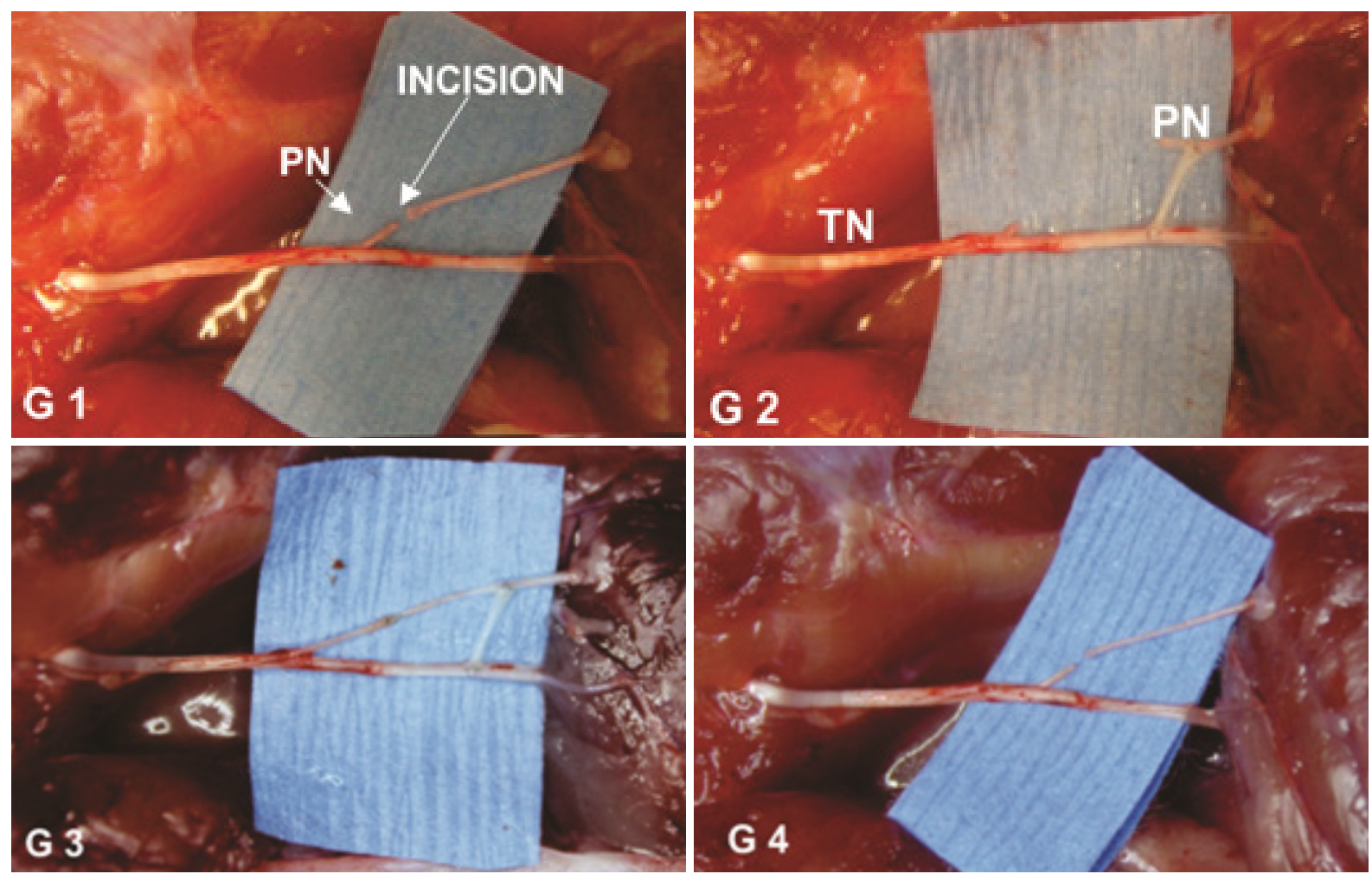

Figure 1: Surgical procedures. G1: Group 1PN neurotomy and repair with EEN; G2: group 2, ESN without end-to-end repair; G3: group 3, both EEN and ESN using a nerve graft; G4: group 4, no repair done. EEN: end-to-end neurorrhaphy; ESN: end-to-side neurorrhaphy; $\mathrm{PN}$ : peroneal nerve; TN: tibial nerve. Optical lenses original magnification $\times 400$ 


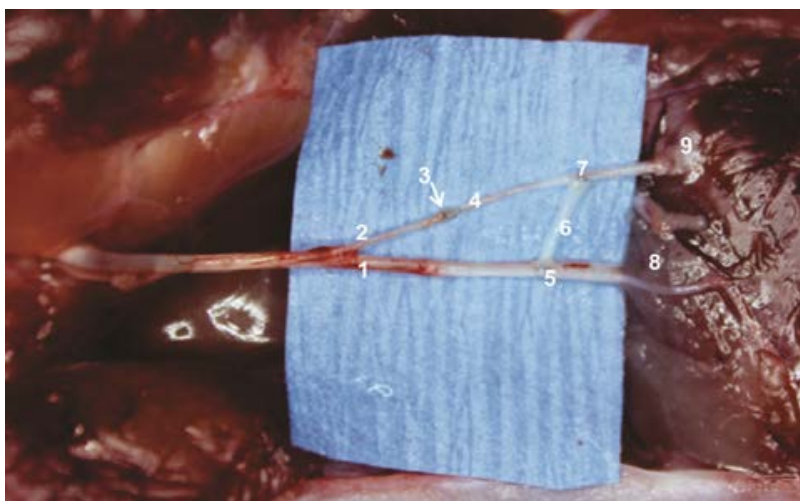

Figure 2: Zones used for microscopic analysis (tibial, peroneal and graft). Optical lenses original magnification $\times 400$

entrance to the muscle. The injury was repaired with an EEN in group 1. In group 2, an ESN was performed from the tibial to the peroneal nerve. In group 3 , a direct EEN plus an ESN neurorrhaphy from the donor nerve (tibial) was used. In both groups 2 and 3 , a nerve graft to bridge the gap between the tibial and peroneal nerves was used. In group 4, only a neurotomy was performed without reconstruction [Figure 1].

\section{Morphological analysis}

Ninety days after neurotomy and repair, the animals were sacrificed with an anesthetic overdose. Nerve fragments from several zones, as well as the corresponding muscles, were identified and marked (z1 to z9) [Figure 2]. These were fixed in a combination of $4 \%$ paraformaldehyde and $2.5 \%$ glutaraldehyde in a saline phosphate buffer solution (0.1 mol/L, $\mathrm{pH} 7.4)$. Following fixation they were treated with $2 \% \mathrm{OsO}_{4}$, dehydrated with ethanol in increasing graduation, and finally placed in epoxic resin (Epon). Axonal diameter and myelin density were determined in 1- $\mu \mathrm{m}$ cross sections dyed with toluidine blue in zones 1 to 9. Axon and muscle ultrastructural analysis was also
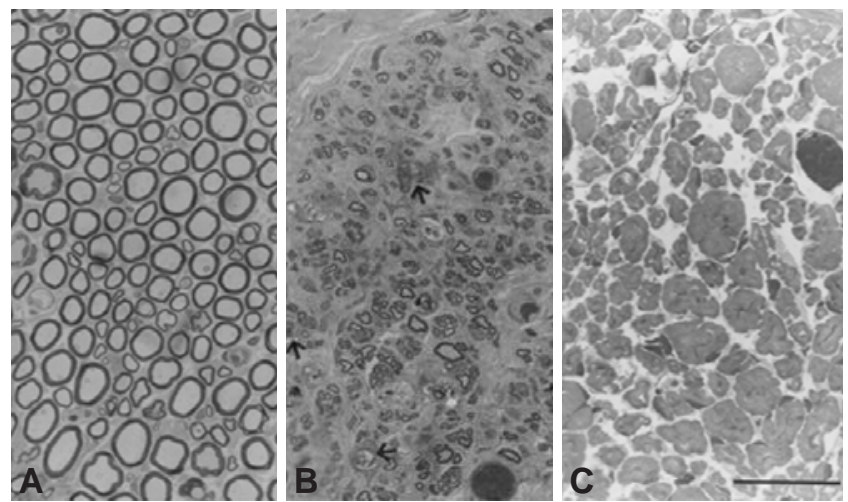

Figure 3: Peroneal nerve cross section in zone 9. A: Group 0 myelinated axons; B: group 3, axonal groups in regenerative process; their size and form are variable, with zones of disorganized myelin (arrows); C: axons in degenerative process were predominant in group 4. Bar $=25 \mu \mathrm{m}$ performed. Muscle cross sections were $60 \mathrm{~nm}$ thick, and viewed with uranyl acetate and lead citrate contrast (Reynolds, 1963) (EM 109 Carl Zeiss). Observations and diameter measurements were made with an Axioscop 2 plus microscope (Carl Zeiss) connected to a system of image analysis. Axiovision 4.0 software was used. All axons on the edges of the cut specimens were excluded from the count.

Statistical analysis was performed using analysis of variance (ANOVA), and an averages comparative analysis (Tukey's method) using Micro Cal Origin software.

\section{RESULTS}

Muscle/nerve morphology, and thickness of the myelin band

The morphology of nerves and muscles was different in all groups. Three morphological conditions were found: normal in group 0; regeneration in groups 1, 2, and 3; and degeneration in groups 1, 2, and 4.

The peripheral region of the nerve displayed large amounts of connective and fatty tissue. In group 0 , the myelinated axons were situated in a semi-circular form, arranged one after another [Figure 3A]; myelin band thickness ranged from 80 to $470 \mathrm{~nm}$, with the diameter of the fiber directly proportional to the thickness of the myelin band [Figure 4A]. In group 3, the main types of fibers were regenerative with a well-defined myelin band, with irregular and grouped dispositions [Figure 3B]. Abundant connective tissue was found among these groups. The thickness of the myelin band varied according to the diameter of the fiber and ranged from 40 to $280 \mathrm{~nm}$ [Figure 4B]. In groups 1 and 2, small regenerative axon fibers were found together with lost myelin architecture or only the

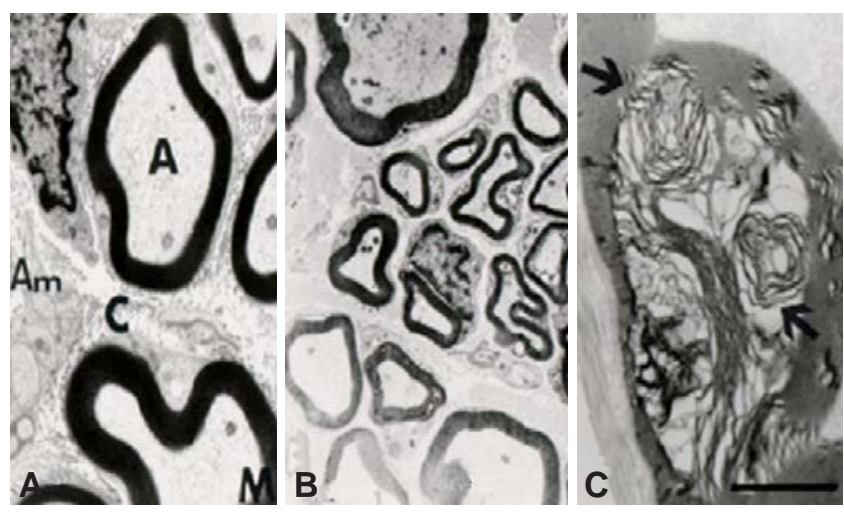

Figure 4: Micrography of myelinated axons. A: Group 0, axons with great diameter with a thick myelin band. A: normal muscle appareance M: normal pattern; Am: intersticium; C: disorganization level; B: group 3 , axons organized in small groups showing regenerative process; C: group 4, disorganized myelin and some myelin remains. Arrows: striated pattern lost and myofibril remains. Bar $=1 \mu \mathrm{m}$ 


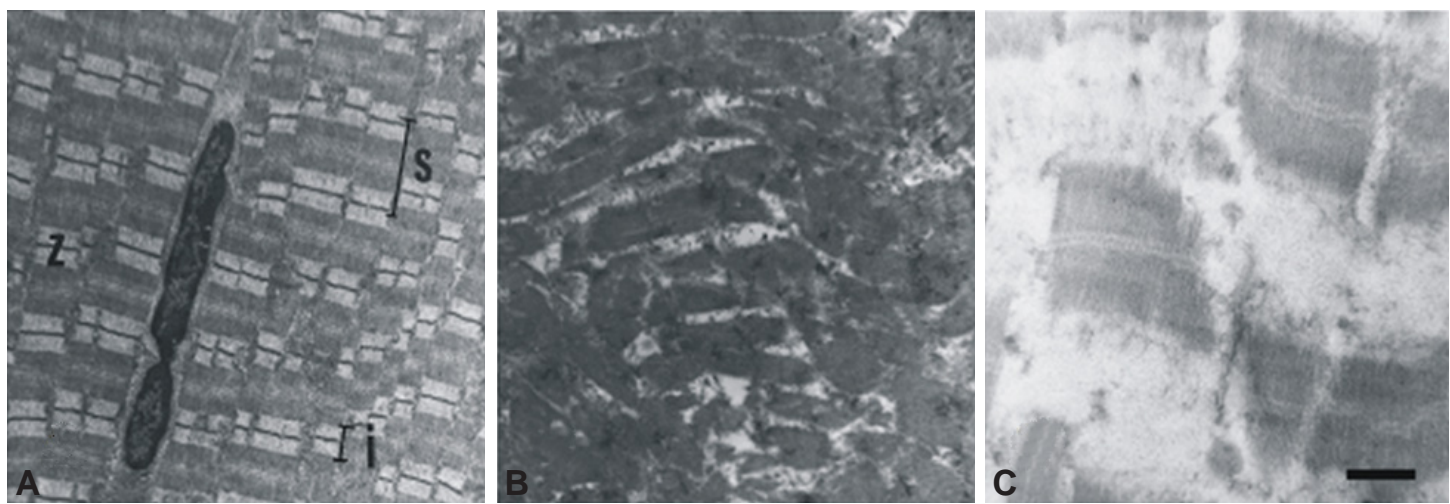

Figure 5: Muscle micrography. A: Represents findings in groups 0 and 3; normal muscle appearance, with normal-appearing transverse striation pattern. $Z=Z$ line, $S=$ sarcomere and $I=$ band. Bar $=500 \mu \mathrm{m}$; B: section showed in the image on the left, zoomed of this normally looking muscle; C: groups 1, 2, and 4 showed different levels of disorganization, striated pattern lost and myofibril remains. Bar $=200 \mu \mathrm{m}$

myelin remains. Animals in group 4 developed a "claw leg" and difficulty with ambulation.

The peroneal nerve lost its form in group 4; through a light microscope, amorphous masses corresponding to be myelinated degenerating axons were observed [Figure 3C]. At an ultrastructural level, it was confirmed that these amorphous masses corresponded to myelin with lost architecture [Figure 4C]. The morphology of the gastrocnemius muscle was normal in all groups. In the tibialis anterior muscle from rats in groups 1 and 2 , zones with muscular fiber disorganization were mixed with others of normal appearance. This muscle was normal in group 3; this group displayed fibers with peripheral nuclei, myofibrils with homologic bands, and fibers which differed from the normal striated pattern [Figure 5A]. In group 4, there was total atrophy of the muscular structure with retained myofibrils [Figure 5B and $\mathrm{C}$ ].

\section{Nerve diameter and axon density}

A difference in the diameter of the peroneal nerve, zone 9, was detected. In addition, decreases in diameter were found in groups $2(28 \pm 1 \mu \mathrm{m})$ and $4(19 \pm 3 \mu \mathrm{m})$; in groups $0(38 \pm 1 \mu \mathrm{m}), 1(31 \pm 6 \mu \mathrm{m})$, and 3 (32 \pm $3 \mu \mathrm{m})$, the diameter was similar, as also found in the grafts in groups 2 and $3(33 \pm 4 \mu \mathrm{m}$ and $31 \pm 3 \mu \mathrm{m}$, respectively).

Axonal fibers were found in the regenerating phase in zones 4, 5, 6, 7, 8, and 9. However, there was only a difference in zone 9 of the peroneal nerve in group 3 in which there was an 18\% increase in comparison with group $0,47 \pm 5 \mu \mathrm{m}$ vs. $39 \pm 4 \mu \mathrm{m}(P<0.001)$. Nonetheless, a decrease was noted in the diameters of fibers in groups 2 and $4(28 \pm 4 \mu \mathrm{m}$ and $13 \pm 4 \mu \mathrm{m}$, respectively), which was statistically significant $(P<$ $0.001)$. The regenerated axon density in the nerve graft was 36\% greater in group 3 than in group 2 (53 $\pm 6 \mu \mathrm{m}$ and $39 \pm 8 \mu \mathrm{m}$, respectively $)(P<0.001)$.

\section{DISCUSSION}

EEN is the most common method used for nerve injury repair, however, in recent years, ESN has become more established as an alternative method for repair of these injuries. ${ }^{[12]}$ According to Battal et al., ${ }^{[13]}$ this is clinically useful when it is performed through an epineural window. It has been proposed that axons may grow through an epineural window in a damaged recipient nerve by means, for instance, of a reversed end-to-side neurorraphy. ${ }^{[1,15]}$ Other studies have demonstrated that operative injury to the donor nerve during ESN is the main prerequisite for motor reinnervation of the recipient nerve. ${ }^{[16]} A$ recent study revealed that performing endto-side coaptation with a $40 \%$ neurectomy showed superior recovery both in axonal regeneration and electrophysiologic parameters. ${ }^{[17]}$ Results are optimized at the microscopic and histopathological levels when a "window" has been performed. ${ }^{[18]}$

In the current study, EEN was combined as a primary method for nerve injury repair with a distal nerve graft used in an ESN manner. As Viterbo et al. ${ }^{[8]}$ has shown previously, the absence of an incision in the donor nerve was not a significant factor that altered the regenerative capacity, neural growth, or transmission of electrical stimuli through the nerve. As a result, animals in groups 1,2, and 3 had a favorable clinical recovery because they did not show alterations during motion, whereas those in group 4 (neurotomy without repair) developed a "clawed" leg without signs of clinical recovery.

In studies performed by Cederna et al., ${ }^{[1]}$ a decrease in metabolically active muscular cells was observed in the muscle innervated by the donor nerve after the epineural window had been made. In his experience, 
this decrease was not significant. This was not observed in the current study. It is possible that neurotomy of the donor nerve, by itself may in fact enhance reinnervation of the recipient nerve, perhaps due to a normal inflammatory response with recruitment of neurotrophic factors. ${ }^{[19]}$

After repair of the neurotomy of the peroneal nerve by means of EEN, and connection to the tibial nerve with an ESN using a neural graft with removal of an epineural window, an $18 \%$ extra-axonal density was obtained closer to the muscle in the group 0 , partially avoiding muscular atrophy and therefore improving the motor and sensory functions.

A novel experimental model using the common peroneal nerve demonstrated that muscle mass preservation was better achieved with sensory reinnervation rather than with motor reinnervation. No differences were found in this model when comparison was made between surgical techniques, whether they were end-to-side or end-to-end. ${ }^{[20]}$

When the group treated with Viterbo's principles (group 2) was compared with our study group (group 3), a similar nerve graft diameter was found, but with a $36 \%$ increase in axonal density in our proposed treatment group.

As a corrective procedure, EEN was combined with a nervous graft coapting the peroneal and tibial nerves through an epineural window by means of an ESN. The number of new neural fibers exceeded those present prior to section of the nerve, indicating a clearly beneficial sensory and motor effect. A significant decrease in axonal size, including the thickness of myelin bands, was accompanied by a regenerative process (sprouting); it is possible that when axons regain their normal size and myelin bands reaches their normal thickness, that the number of axons be equal to the number of axons in the group 0 . Although the current study protocol required that study subjects be sacrificed to obtain muscle and nerve samples, it would be interesting to measure this parameter in a later study. It is now accepted that collateral sprouting is the main mechanism of nerve regeneration following end-to-side neurorrhaphies. ${ }^{[17]}$ Haninec et al.. ${ }^{[21]}$ conducted a study to determine the utility of ESN from C5 to the ulnar nerve for motor and sensory reinnervation. More collateral branches were found in the group in which a perineural window had been performed. Although direct implantation of fibers into the target muscle has been recently performed, it can be avoided by performing an end-to-side procedure as proposed by Poppler et al. ${ }^{[22]}$
The current study demonstrates the clinical importance of limiting muscular damage by using a "babysitter" to preserve motor function after proximal nerve injuries in the upper extremity before muscle atrophy is completely established. Several factors may alter the result. First, both the injury mechanism and the experimental model are crucial. Crush injury distal to the coaptation site has been found to increase the rate of myelin formation in regenerating axons. ${ }^{[23]}$ Further research is required to determine the role of pre-injury, as deliberate donor nerve axotomy is critical for optimization of motor neural regeneration as demonstrated in several studies. ${ }^{[16-18]}$ Recent research suggests that the number of axonal sprouts correlate with the degree of donor nerve manipulation secondary to liberation of neurotrophic factors, rather than the extent of the axotomy per se. ${ }^{[24]}$

The results of the current study suggest that the same surgical principals can be applied to clinical practice with patients. Clinical recovery is potentially faster and more efficient as the distance for nerve growth is shortened with the nerve graft placed near to the muscle rather than waiting for normal axonal growth from the injury's site of origin. With the proposed treatment, irreversible muscular atrophy was avoided by supplying the target muscles with a constant neural impulse by means of this babysitter procedure. ${ }^{[25]}$ Several applications for the ESN are currently being studied. ${ }^{[26-30]}$ The authors of the current study intend to study the usefulness of this procedure in the scenario of acute trauma of the upper limb by creating nerve bridges at the wrist crease in order to ameliorate ulnar nerve injury, as it has been found that intrinsic muscle function tends to be compromised despite the efforts of a primary end-to-end repair.

In conclusion, this study revealed a lower index of muscle fiber destruction, and can be a reliable method for reconstruction in high neural injuries. These results may assist surgeons in the treatment of high neural injuries in humans by performing nerve bridges at the level of the wrist.

\section{Financial support and sponsorship}

None.

\section{Conflicts of interest}

There are no conflicts of interest.

\section{Patient consent}

There were no patients involved.

\section{Ethics approval}

The Ethics and Investigation Committees reviewed and approved the investigation protocol (Protocol no. 
081/97). The animals were treated according to the Recommendations of Care and Use of Laboratory Animals (NIH publication no. 85-23, reviewed 1985, US Government Printing Office, Washington, DC) and according to the recommendations of source country (NOM-062-ZOO-1999).

\section{REFERENCES}

1. Cederna PS, Kalliainen LK, Urbanchek MG, Rovak JM, Kuzon WM Jr. "Donor" muscle structure and function after end-to-side neurorrhaphy. Plast Reconstr Surg 2001;107:789-96.

2. Giovanoli P, Koller R, Meuli-Simmen C, Rab M, Haslik W, Mittlböck M, Meyer VE, Frey M. Functional and morphometric evaluation of end-to-side neurorrhaphy for muscle reinnervation. Plast Reconstr Surg 2000;106:383-92.

3. Beris A, Lykissas M, Korompilias A, Mitsionis G. End-to-side nerve repair in peripheral nerve injury. J Neurotrauma 2007;24:909-16.

4. Battal MN, Hata Y. A review on the history of end-to-side neurorrhaphy. Plast Reconstr Surg 1997;99:2110-1.

5. Bontioti E, Kanje M, Lundborg G, Dahlin LB. End-to-side nerve repair in the upper extremity of rat. J Peripher Nerv Syst 2005;10:58-68.

6. Kalliainen LK, Cederna PS, Kuzon WM Jr. Mechanical function of muscle reinnervated by end-to-side neurorrhaphy. Plast Reconstr Surg 1999;103:1919-27.

7. Viterbo F, Trinidade JC, Hoshino K, Mazzoni Neto A. End-to-side neurorrhaphy with removal of the epineural sheath: an experimental study in rats. Plast Reconstr Surg 1994;94:1038-47.

8. Viterbo F, Trinidade JC, Hoshino K, Mazzoni A. Two end-to-side neurorrhaphies and nerve graft with removal of the epineural sheath: experimental study in rats. Br J Plast Surg 1994;47:75-80.

9. Frey M, Giovanoli P, Michaelidou M. Functional upgrading a partially recovered facial palsy by cross-face nerve grafting with distal end-toside neurorrhaphy. Plast Reconstr Surg 2006;117:597-608.

10. May M, Sobol SM, Mester SJ. Hypoglossal-facial nerve interpositional-jump graft for facial reanimation without tongue atrophy. Otolaryngol Head Neck Surg 1991;104:818-25.

11. Sundine MJ, Quan EE, Saglam O, Dhawan V, Quesada PM, Ogden L, Harralson TG, Gossman MD, Maldonado CJ, Barker JH. The use of end-to-side nerve grafts to reinnervate the paralyzed orbicularis oculi muscle. Plast Reconstr Surg 2003;111:2255-64.

12. Papalia I, Geuna S, D'Alcontres FS, Tos P. Origin and history of end to side neurorrhaphy. Microsurgery 2007;27:56-61.

13. Battal NM, Hata $\mathrm{Y}$, Matsuka $\mathrm{K}$, It $\mathrm{O}$, Matsuda $\mathrm{H}$. Cross facial nerve grafting by end-to-side neurorrhaphy with or without removal of the epineurium in rats. J Jpn Plast Reconstr Surg 1996;16:641-7.

14. Isaacs J, Allen D, Chen LE, Nunley J 2nd. Reverse end-to-side neurotization. J Reconstr Microsurg 2005;21:43-8; discussion 49-50.

15. Li Q, Zhang P, Yin X, Jiang B. Early nerve protection with anterior interosseus nerve in modified end-to-side neurorraphy repairs high ulnar nerve injury: a hypothesis of a novel surgical technique. Artif Cells Nanomed Biotechnol 2015;43:103-5.

16. Brenner MJ, Dvali L, Hunter DA, Myckatyn TM, Mackinnon SE. Motor neuron regeneration through end-to-side repairs is a function of donor nerve axotomy. Plast Reconstr Surg 2007;120:215-23.

17. Liu HF, Chen ZG, Shen HM, Zhang H, Zhang J, Lineaweaver WC, Zhang F. Efficacy of the end-to-side neurorraphies with epineural window and partial donor neurectomy in peripheral nerve repair: an experimental study in rats. J Reconstr Microsurg 2015;31:31-8.

18. Zhang Z, Soucacos PN, Beris AE, Bo J, Ioachim E, Johnson EO Long term evaluation of rat peripheral nerve repair with end-to-side neurorrhaphy. J Reconstr Microsurg 2000;16:303-11.

19. Pondaag W, Gilbert A. Results of end-to-side nerve coaptation in severe obstetric brachial plexus lesions. Neurosurgery 2008;62:656-63.

20. Yoshitatsu S, Matsuda K, Yano K, Hosokawa K, Tomita K. Muscle flap mass preservation by sensory reinnervation with end-to-side neurorraphy: an experimental study in rats. $J$ Reconstr Microsurg 2008;24:479-87.

21. Haninec P, Kaiser R, Dubový P. A comparison of collateral sprouting of sensory and motor axons after end-to-side neurorrhaphy with and without the perineurial window. Plast Reconstr Surg 2012;130:609-14.

22. Poppler LH, Wood MD, Hunter DA, MacKinnon SE, Moore AM. A reverse end-to-side sensory nerve transfer preserves muscle mass. Plast Reconstr Surg 2014;134:39-40.

23. Kokkalis ZT, Soucacos PN, Terzis JK. Effect of donor nerve injury distal to an end-to-side neurorrhaphy model. J Reconstr Microsurg 2009;25:295-306

24. Bao Q, Xiao C, Wang T, Gu Y. Novel atraumatic end-to-side repair model exhibits robust collateral sprouting independent of donor fiber injury. Plast Reconstr Surg 2016;137:523-33.

25. Davidge KM, Yee A, Moore AM, Mackinnon SE. The supercharge end-to-side anterior interosseous-to-ulnar motor nerve transfer for restoring intrinsic function: clinical experience. Plast Reconstr Surg 2015;136:e344-52.

26. Łukaszuk M, Kwiecień G, Madajka M, Uygur S, Drews M, Siemionow M. Repair of the peripheral nerve gap with epineural sheath conduit to prevent muscle denervation atrophy in the diabetic rat model. Pol Przegl Chir 2013;85:387-94.

27. Siemionow M, Uygur S, Ozturk C, Siemionow K. Techniques and materials for enhancement of peripheral nerve regeneration: a literature review. Microsurgery 2013;33:318-28.

28. Tos P, Colzani G, Ciclamini D, Titolo P, Pugliese P, Artiaco S. Clinical applications of end-to-side neurorrhaphy: an update. Biomed Res Int 2014;2014:646128.

29. Fagotti de Almeida CE, Farina Junior JA, Colli BO. Morphometric and functional analysis of axonal regeneration after end-to-end and end-to-side neurorrhaphy in rats. Plast Reconstr Surg Glob Open 2015;3:e326.

30. Song C, Oswald T, Yan H, Chen MB, Zhang J, Chen T, Lineaweaver WC, Zhang F. Repair of partial nerve injury by bypass nerve grafting with end-to-side neurorraphy. J Reconstr Microsurg 2009;25:507-15. 